\title{
Perforación esofágica durante el monitoreo intraoperatorio con ecocardiografía transesofágica. Reparación en el mismo acto quirúrgico
}

\author{
Esophageal injury secondary to transesophageal \\ ecocardiography monitoring and repair
}

José M. Pastor ${ }^{1}$, Macagno Diego²

\begin{abstract}
Monitoring with intraoperative Transesophageal Echocardiography (TEE) has proven to be a tool of very high utility for both control of the hemodynamic status, cardiac function and to make new diagnoses. It is a minimally invasive technique and, like any medical procedure, it is not exempt from complications that do not exceed $1 \%$. These range from mild oropharyngeal lesions to the most serious lesion, esophageal perforation. We describe a case of esophageal perforation from the esophagogastric junction to the middle third of the esophagus in the intraoperative period of laparoscopic Nissen surgery. The injury was repaired immediately and the closure of the lesion was verified with pneumatic maneuvers through the nasogastric tube. The patient was discharged after 35 days
\end{abstract}

\section{RESUMEN}

El monitoreo con Ecocardiografía Transesofágica intraoperatorio (ETE) ha demostrado ser una herramienta de muy alta utilidad tanto para control del estado hemodinámico, función cardíaca y para realizar nuevos diagnósticos. Se trata de una técica seiinvasiva y como todo procedimiento médico no está exento de complicaciones que no superan al $1 \%$. Estas son desde lesiones leves orofaríngeas
Key words:

Intraoperative transesophageal echocardiography, complications

Palabras clave: Ecocardiografia transesofágica intraoperatoria, complicaciones

Consultor en anestesiología, Maestría en ETE (Sociedad Española de Imágenes cardíacas).

MAAC - FACS.

Fecha de recepción: 15 de mayo de 2018

Fecha de aceptación: 25 de agosto de 2018

\section{ORCID}

https://orcid.org/000-0003-2172-908

Correspondencia:

José M. Pastor

Email: dr.jmpastor@gmail.com 
hasta la lesión más grave que es la perforación esofágica. Se describe un caso de perforación esofágica con desgrarro de éste desde la unión esofagogástrica hacia el tercio medio del esófago en el íntraoperatorio de cirugía de Nissen laparoscópico. La reparación de la injuria se realizó en forma inmediata y se comprobó con maniobras neumáticas a través de la sonda nasogástrica el cierre de la lesión. La paciente fue dada de alta a lo 35 días.

\section{Caso clínico}

$\mathrm{P}$ aciente masculino de 75 años sin antecedentes de patología esofágica, con antecedentes de esclerosis valvular aórtica severa e insuficiencia mitral leve, capacidad funcional disminuida y antecedentes de trombosis venosa profunda (TVP) hace aproximadamente dos años. Electrocardiograma en ritmo sinusal con hemibloqueo izquierdo anterior con $T$ negativa en cara inferior y antero lateral ya registrado en un ECG del 26/02/2013.

Ingresó a quirófano con diagnóstico de hernia hiatal gigante con deslizamiento y vólvulo gástrico intratorácico para realización de un Nissen laparoscópico (Figura 1).

Una vez realizada la inducción anestésica y con el paciente intubado, se introdujo el transductor multiplanar para monitoreo intraoperatorio. Los movimientos ascendentes y descendentes fueron sin esfuerzo y siguiendo las guías de la Society of Cardiovascular Anesthesiologists[2].

Después de valorar el grado de esclerosis aórtica y comprobar una leve insuficiencia mitral[3], se determinó la función sistólica y diastólica en ventana medioesofágica baja de 4 cámaras con Doppler tisular. El transductor se mantuvo frizado en esta ventana durante la cirugía

Mientras el transductor se encontraba en esófago medio se observó la punta del mismo en el medio de la pantalla del laparoscopio y cuando se comienzó a retirar se desgarró el esófago desde la unión esofogástrica hacia tercio medio de aproximadamente 4 a $6 \mathrm{~cm}$.

Inmediatamente se reparó con puntos separados de Monocryl 4.0. Y luego para comprobar la impermeabilidad de la sutura se realizó a través de la sonda nasogástrica pruebas neumáticas para comprobar la permeabilidad del surget.

Se realizó el cierre del orificio herniario, no realizando la fundoplicatura para disminuir la presión a la rafia esofágica. Yeyunostomía de alimentación y se colocaron 2 drenajes, uno mediastínico en posición de la rafia esofágica y otro en el abdomen.
El paciente evolucionó hemodinámicamente estable y permaneció en la unidad de terapia intensiva durante 24 h y luego pasó a la sala de internación de cirugía.

Evolucionó favorablemente con tratamiento médico, antibiótico, y alimentación enteral.

A los 10 días del posoperatorio se retiró la sonda nasogástrica y comenzó con prueba a tolerancia de líquidos. Evolucionó estable, pero, al día 11 se constató líquido seroso salival en el drenaje y salida por el mismo del líquido que consumía determinándose con azul de metileno una fístula de la rafia esofágica.

Se continúó entoces con nutrición enteral, antibióticos y se suspendió la ingesta oral.

A los 16 días se volvió a estudiar el tránsito digestivo con seriada esofagogástrica con contraste hidrosoluble y mostró buen pasaje esofagogástrico con estrechez del esófago y fuga a nivel del 1/3 distal del mismo (Figura 2).

El día 26 se realizó una nueva serie de radiografías esofagogástricas y esta vez no se constató fuga (Figura 3).

A los 30 días, no presentó disfagia y se indicó dieta procesada. Toleró líquidos.

A los 34 días fue dado de alta y su seguimiento fue realizado en el consultorio externo.

\section{Discusión}

El monitoreo con ETE es un método semiinvasivo

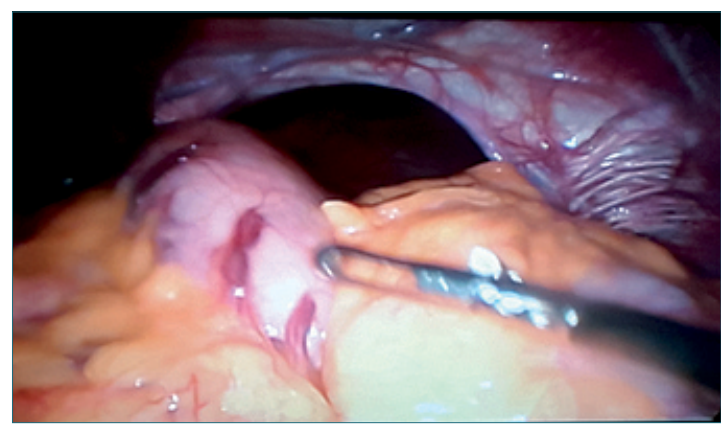

Figura 1. Imágen laparoscópica que demuestra la gran hernia hiatal. 


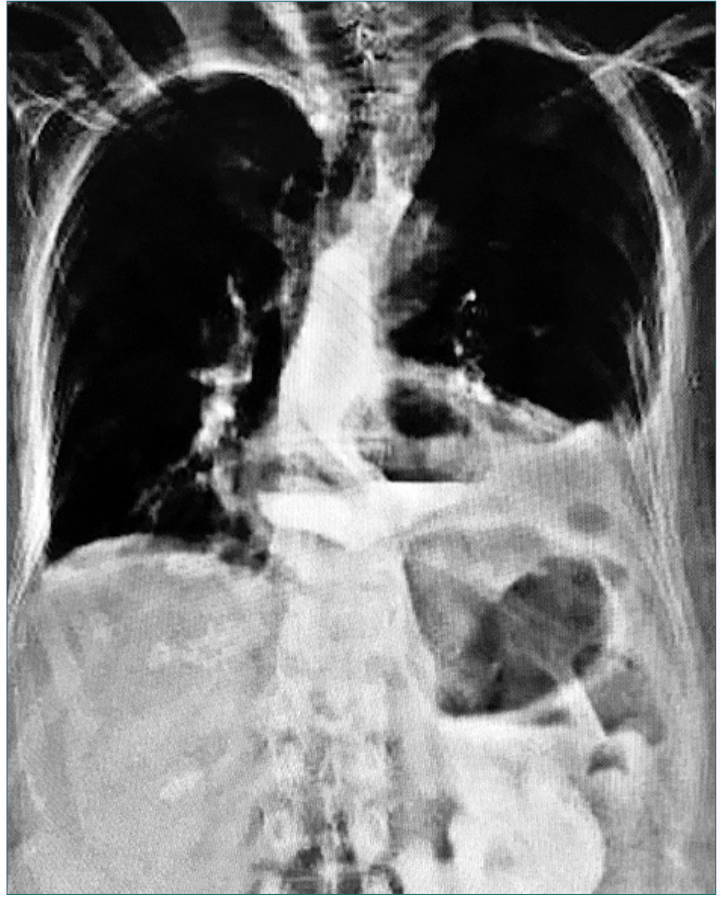

Figura 2. Estrechez de esófago y fuga en tercio distal.

que comienza a utilizarse hace 30 años para el monitoreo de los pacientes de cirugía cardíaca en especial de aquellos que se beneficiaban con el recambio o reparo valvular[3]. Sus ventajas hicieron que rápidamente se extendiera como monitoreo intraopertaorio (IOP) en el escenario de la cirugía cardiovascular[4].

El desarrollo de equipos más portátiles, el aumento de las comorbilidades que acompañan a los pacientes mayores y la rápidas respuestas que nos da el ETE a las preguntas que nos hacemos ante una alteración HD durante el IOP generó un nuevo paradigma y las indicaciones del ETE. se entendió a la cirugía no cardíaca[5].

Como todo nuevo sistema de monitoreo tiene sus ventajas y desventajas entre estas últimas la más temida es la perforación de esófago. En una revisión sistemática de Perforación esofágica inducida por ETE[6] los autores describen dos mecanismos de perforación. Uno por el estacionamiento continuo del transductor en el esófago torácico que puede provocar un trauma mecánico indirecto cuando se lo deja por tiempo prolongado en pacientes sometidos a cirugía de revascularización miocárdica con patología arteriosclerótica y baja perfusión de la mucosa esofágica. Segundo, en el intento de obtener buenas imágenes en el eje corto transgástrico con máxima anteflexión del transductor

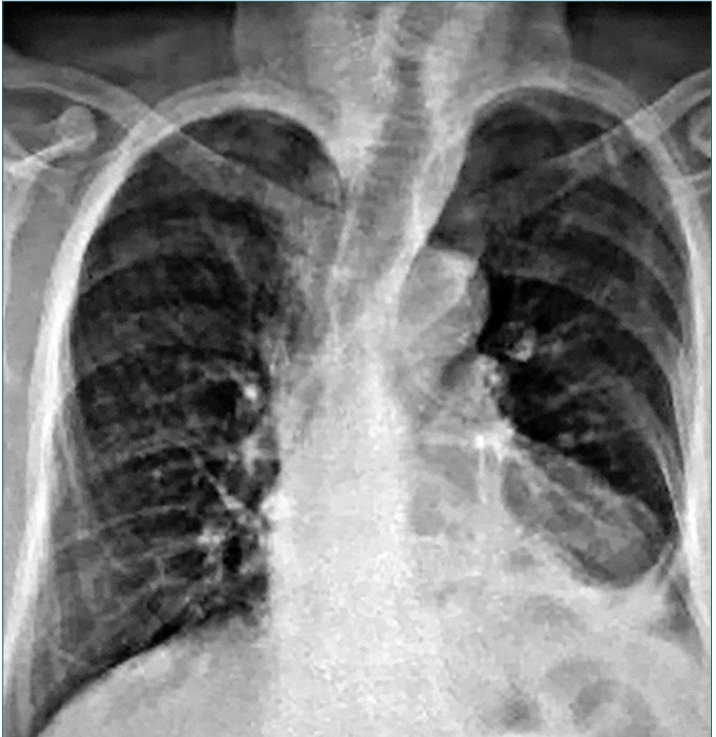

Figura 3. Ausencia de filtración esofágica.

puede asociarse a una lesión mecánica directa del esófago distal o de la unión gastroesofágica.

La frecuencia promedio de perforación esofágica completa es de 0,03\% y 0,09\% según los estudios publicados[7,8] y la mortalidad alcanzaría 28,5\% cuando no es diagnosticada en forma inmediata, estuvo asociada con shock en su presentación o se asocia a una mediastinitis. Este caso particular describió la presencia de la punta del transductor saliendo por un orifico en la pared anterior del esófago en la pantalla del laparoscopio que no tiene relación con los mecanismos de lesión antes propuestos. Se describe, entonces, un nuevo mecanismo de lesión dado por la tracción del el cirujano del esófago y la mantención del transductor en movimiento, lo que provocó la perforación. Además al retirar en forma inmediata el transductor se produjo el desgarro.

El cirujano utilizó el cierre con puntos separados de Monocryl y a través de la SNG se inyectó aire y cuando se comprobó la ausencia de fugas por la pared reparada se continuó la cirugía con la reparación de la hernia evitando la fundoplicatura para disminuir la presión de la rafia y se finalizó con yeyunostomía y colocación de dos drenajes uno mediastínico y otro abdominal.

En conclusión, si bien la ETE es una técnica segura y con baja incidencia de complicaciones, éstas pueden ser un poco más frecuentes si se trata de cirugías del tubo gastrointestinal y no hay coordinación entre el cirujano y el anestesiólogo entre los movimientos quirúrgicos y los del transductor. 


\section{Referencias}

1. Kallmeyer IJ, Collard CD, Fox JA, Body SC, Shernan SK. The safety of intraoperative transesophageal echocardiography: a case series of 7200 cardiac surgical patients. Anesth Analg. 2001 May;92(5):1126-30.

2. Hahn RT, Abraham T, Adams MS, Bruce CJ, Glas KE, Lang RM, et al.; American Society of Echocardiography; Society of Cardiovascular Anesthesiologists. Guidelines for performing a comprehensive transesophageal echocardiographic examination: recommendations from the American Society of Echocardiography and the Society of Cardiovascular Anesthesio- logists. Anesth Analg. 2014 Jan;118(1):21-68.

3. Bach DS, Deeb GM, Bolling SF. Accuracy of intraoperative transesophageal echocardiography for estimating the severity of functional mitral regurgitation. Am J Cardiol. 1995 Sep;76(7):508-12.

4. Eltzschig $H K$, Rosenberger $P$, Löffler M, Fox JA, Aranki SF, Shernan SK. Impact of intraoperative transesophageal echocardiography on surgical decisions in 12,566 patients undergoing cardiac surgery. Ann Thorac Surg. 2008 Mar;85(3):845-52.

5. Cabrera Shulmeyer MC. Ecocardiografía transesofágica durante Cirugía no Cardíaca. Rev Chil Anest. 2017;46(1):8-13.
6. Sainathan S, Andaz S. A systematic review of transesophageal echocardiography-induced esophageal perforation. Echocardiography. 2013 Sep;30(8):977-83.

7. Min JK, Spencer KT, Furlong KT, DeCara JM, Sugeng L, Ward RP, et al. Clinical features of complications from transesophageal echocardiography: a singlecenter case series of 10,000 consecutive examinations. J Am Soc Echocardiogr. 2005 Sep;18(9):925-9.

8. Piercy M, McNicol L, Dinh DT, Story DA, Smith JA. Major complications related to the use of transesophageal echocardiography in cardiac surgery. J Cardiothorac Vasc Anesth. 2009 Feb;23(1):62-5. 